\title{
Отечественные помехоподавляющие керамические фильтры Б33 для поверхностного монтажа
}

\author{
В. Смирнов, к.т.н., А. Харитонов ${ }^{1}$, А.Шалаева², А. Сак ${ }^{3}$
}

УДК 621.319.4 | ВАК 05.27 .01

\begin{abstract}
За последние годы в АО «НИИ «Гириконд» была разработана серия керамических помехоподавляющих фильтров в корпусном исполнении Б25, Б26, Б27, Б30. Однако по мере увеличения плотности компоновки элементной базы для подавления помех во вторичных цепях постоянного тока у отечественной промышленности появилась потребность в керамических фильтрах для поверхностного монтажа. На базе современных керамических материалов, технологий и оборудования в АО “НИИ "Гириконд" разработаны и освоены в производстве помехоподавляющие керамические фильтры Б33 для поверхностного монтажа С-типа. Рассмотрим конструкцию, параметры и особенности применения предлагаемых устройств.
\end{abstract}

ильтры 533 - это многослойные трехвыводные керамические чип-конденсаторы (рис. 1). Два вывода (1 и 2), соединенные с проходными электродами, расположены на противоположных торцевых поверхностях, третий вывод (3) для отвода помех на землю находится по центру боковых поверхностей. Чип-фильтры выпускаются в шести габаритных размерах: 1,6×0,8; $2 \times 1,25 ; 3,2 \times 1,25 ; 3,2 \times 1,6 ; 4,5 \times 1,6$ и 5,7×5,0 мм [1]. Плани-

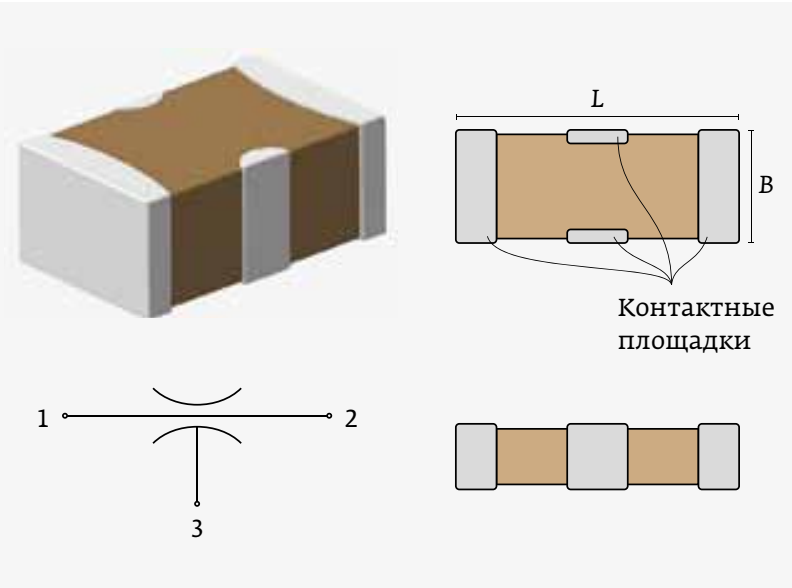

Рис. 1. Конструкция чип-фильтров С-типа

АО «НИИ «Гириконд», врио начальника лаборатории керамических фильтров, тел.: +7 812 247-14-53.

АО «НИИ «Гириконд".

АО «НИИ "Гириконд", начальник НПК керамических конденсаторов и фильтров, тел.: +7 812 552-21-66. руется также дополнить линейку устройством габаритами 4,5×3,2 мм.

В производстве фильтров 533 используется высокопроизводительное оборудование словенской компании КЕКО (рис. 2). Оно позволяет одновременно обрабатывать групповые пакеты, состоящие из 11000 заготовок фильтров размером 1,6×0,8 мм и 500 заготовок размером 5,7×5,0 мм.

Внутренние электроды фильтров изготовлены на основе сплава, состоящего из 70\% серебра и 30\% палладия, внешние электроды (контактные площадки) - из серебра, никеля и олова. Фильтры предлагаются в трех группах температурной стабильности (ТСЕ): МП0, Н20 и Н50 с рабочими температурами от -60 до $125^{\circ} \mathrm{C}$. В качестве материала диэлектрика для всех групп ТСЕ использованы созданные в АО «нИИ «Гириконд" керамические материалы с диэлектрической проницаемостью $\varepsilon=29$ и 90

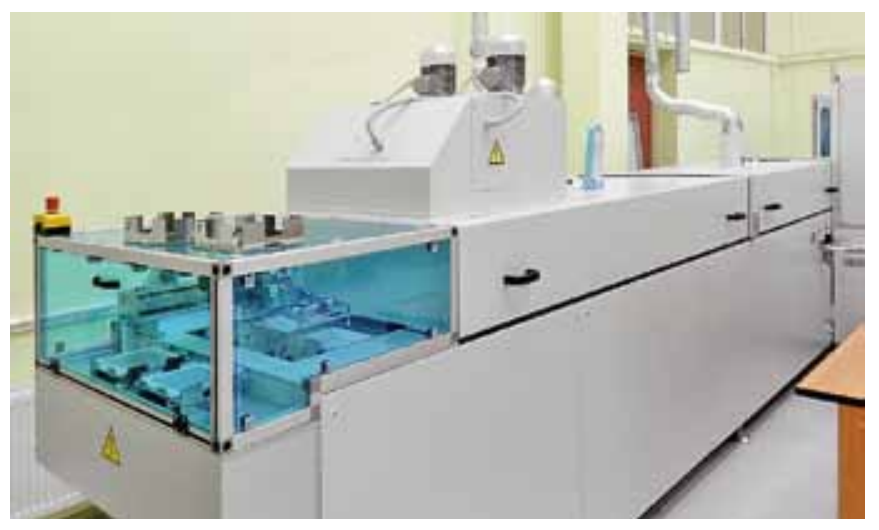

Рис. 2. Оборудование компании КЕКО 


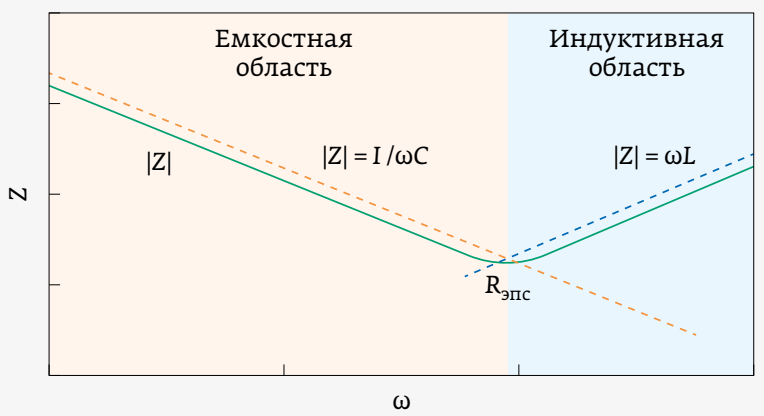

Рис. 3. Частотная зависимость полного сопротивления $\mathrm{Z}$ фильтров С-типа

по группе МПо, $\varepsilon=3100-3700$ по группе H20 и $\varepsilon=4500$ по группе $\mathrm{H} 50$.

В табл. 1 представлены основные параметры фильтров, в том числе группы ТСЕ, номинальные емкости, напряжения и токи для всех габаритных размеров, а также дано сравнение с зарубежными аналогами. Введение габаритного размера 5,7×5,0 мм, снятого с производства зарубежными компаниями, объясняется востребованностью данного варианта исполнения в отечественной радиоаппаратуре
Частотная зависимость полного сопротивления Z фильтров приведена на рис. 3. Она имеет U-образную форму, в левой ветви которой Z уменьшается пропорционально частоте и достигает минимального значения на частоте собственного последовательного резонанса $f_{\text {рез. }}$. На этой частоте величины емкостного и индуктивного реактивных сопротивлений равны и противоположны по знаку, а результирующее реактивное сопротивление равно нулю. На частоте $f_{\text {рез }}$ общий импеданс равен эквивалентному последовательному сопротивлению $\mathrm{R}_{\text {эпс }}$ которое определяется активным сопротивлением электродов и контактных узлов. На частотах ниже $f_{\text {рез }}$ полное сопротивление $Z$ определяется емкостью, а на частотах выше $f_{\text {рез }}$ - индуктивностью, увеличиваясь пропорционально частоте. Помехоподавление обеспечивается при помощи отведения помехи на землю через сопротивление $\mathrm{R}_{\text {эп }}$.

Основная характеристика помехоподавления фильтра - вносимое затухание $A$, которое вычисляется по формуле:

$$
A=20 \lg U_{1} / U_{2}
$$

где $\mathrm{U}_{1}$ - напряжение в цепи без фильтра, $\mathrm{U}_{2}$ - напряжение с установленным фильтром.
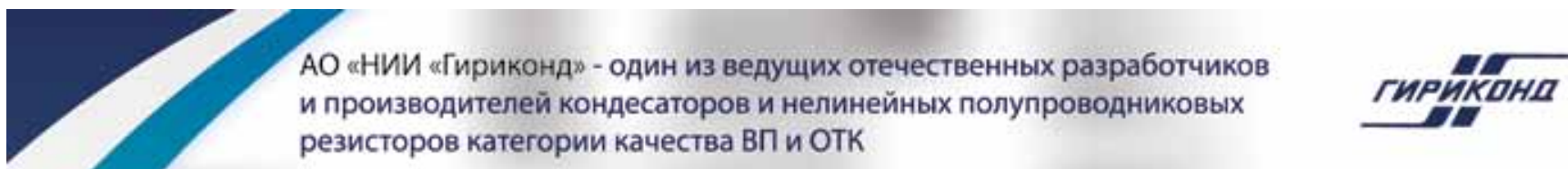
резисторов категории качества ВП и ОТК

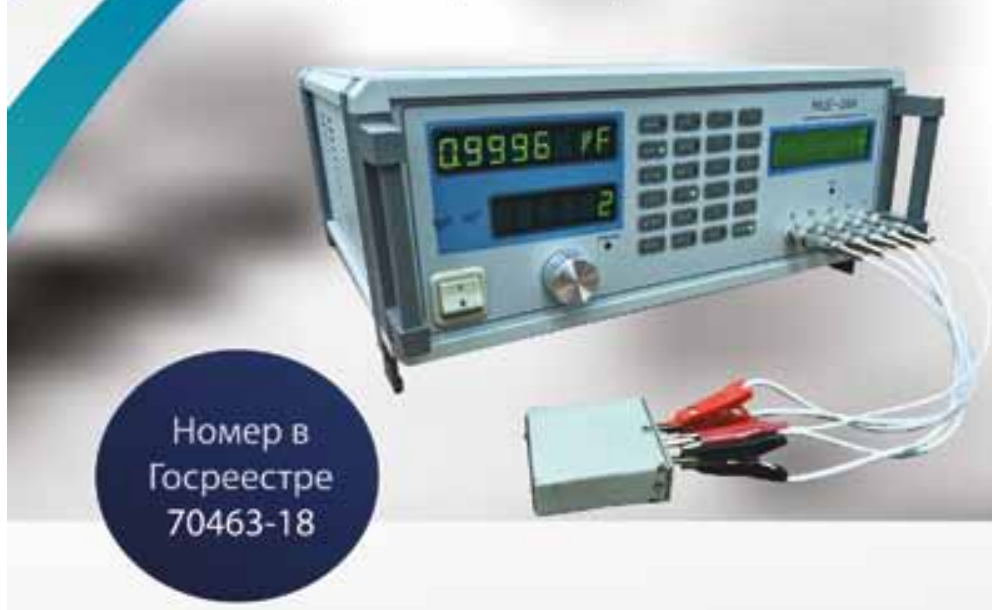

\section{ПРИБОР МЦЕ-26А}

Прибор предназначен для измерения на частоте 1 кГц электрической ёмкости и тангенса угла потерь конденсаторов и их разбраковки по электрической ёмкости и тангенсу угла потерь.

При измерении используется эквивалентная параллельная двухэлементная схема замещения конденсатора.

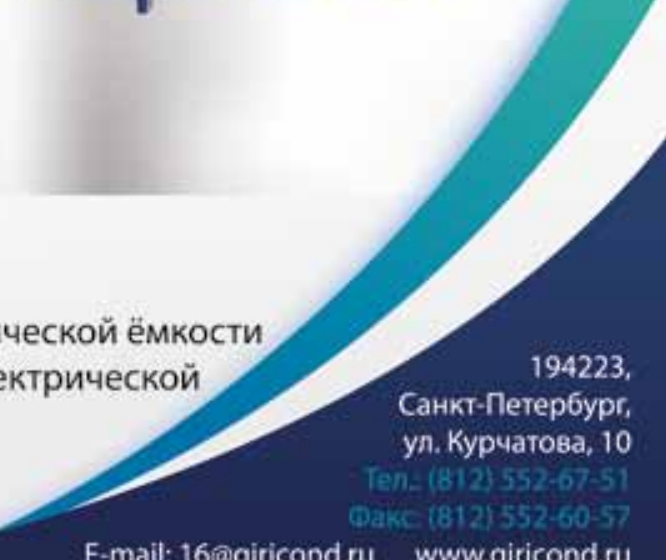

E-mail:16@giricond.ru www.giricond.ru 
Таблица 1. Сравнение шкалы типономиналов фильтров Б33 и зарубежных аналогов

\begin{tabular}{|c|c|c|c|c|c|c|c|c|c|c|c|}
\hline \multirow{3}{*}{$\begin{array}{l}\text { Габарит, мм, } \\
\text { (код), } \\
\text { группа ТКЕ }\end{array}$} & \multirow{3}{*}{$\begin{array}{c}U \\
B\end{array}$} & \multicolumn{2}{|l|}{533} & \multicolumn{2}{|c|}{ API (Spectrum Control) } & \multicolumn{2}{|l|}{ Syfer } & \multicolumn{2}{|l|}{ AVX } & \multicolumn{2}{|l|}{ Murata } \\
\hline & & $C_{1}$ & $I_{\text {ном' }}$ & $C_{1}$ & $I_{\text {макс' }}$ & $C_{1}$ & $I_{\text {макс' }}$ & $C_{1}$ & $I_{\text {макс' }}$ & $C_{1}$ & $I_{\text {мak' }}$ \\
\hline & & МкФ & A & МкФ & A & МкФ & A & МКФ & $A$ & МКФ & $A$ \\
\hline \multirow{3}{*}{$\begin{array}{l}1,6 \times 0,8 \\
(0603), \\
\text { МП0 }\end{array}$} & 16 & $680 п Ф$ & 1 & & & & & & & & \\
\hline & 25 & $330,470 \sqcap \Phi$ & 0,7 & & & & & & & & \\
\hline & 50 & $22-220 \pi \Phi$ & $0,5-1$ & $22-220 \pi \Phi$ & 0,3 & & & & & & \\
\hline \multirow{4}{*}{$\begin{array}{l}1,6 \times 0,8 \\
(0603), \\
\mathrm{H} 20(\mathrm{H} 50)\end{array}$} & \multirow{2}{*}{16} & \multirow{2}{*}{$0,022(0,033)$} & \multirow{2}{*}{1} & & & & & & & $100 п \Phi-0,022$ & 0,5 \\
\hline & & & & & & & & & & $0,022-1,0$ & 2 \\
\hline & 25 & $\begin{array}{c}6800 \text { пФ; } \\
0,01(0,015)\end{array}$ & $0,5(1)$ & $0,022(0,1)$ & $\begin{array}{l}0,5 \\
(1)\end{array}$ & & & & & & \\
\hline & 50 & $\begin{array}{c}470-4700 п \Phi \\
(6800 п \Phi)\end{array}$ & $0,3(0,7)$ & $470-2200$ пФ & 0,3 & & & & & & \\
\hline \multirow{6}{*}{$\begin{array}{l}2 \times 1,25 \\
(0805) \\
\text { МП0 }\end{array}$} & 16 & $2200 \pi \Phi$ & 1 & & & & & & & & \\
\hline & 25 & 1500 пФ & 1 & & & $180-1500$ пФ & 0,$3 ; 1$ & & & & \\
\hline & \multirow[b]{2}{*}{50} & \multirow[b]{2}{*}{$680 ; 1000 п \Phi$} & \multirow[b]{2}{*}{0,5} & \multirow[b]{2}{*}{$22-220 п \Phi$} & \multirow[b]{2}{*}{0,4} & $22-820 \pi \Phi$ & 0,3 & & & & \\
\hline & & & & & & $10-220 п \Phi$ & 1 & & & & \\
\hline & \multirow{2}{*}{100} & \multirow{2}{*}{$10-470 п Ф$} & \multirow{2}{*}{0,3} & & & $22-560 \pi \Phi$ & 0,3 & \multirow{2}{*}{$22-470 п Ф$} & \multirow{2}{*}{0,5} & & \\
\hline & & & & & & $10-120 п Ф$ & 1 & & & & \\
\hline \multirow{9}{*}{$\begin{array}{l}2 \times 1,25 \\
(0805) \\
\mathrm{H} 20(\mathrm{H} 50)\end{array}$} & \multirow{2}{*}{16} & 0,068 & \multirow{2}{*}{$1-2(2)$} & & & & & & & 0,$22 ; 0,47$ & 2 \\
\hline & & $0,1(0,15)$ & & & & & & & & 1,0 & 4 \\
\hline & & & & & & $470 п Ф-0,1$ & 0,3 & & & & \\
\hline & 25 & 0,$033 ; 0,04 /(0,068)$ & $0, /(2)$ & & & $820 п Ф-0,1$ & 1 & 0,1 & 2 & 0,1 & 2 \\
\hline & & & & $470-2200$ пФ & 0,4 & $560 \sqcap \Phi-0,068$ & 0,3 & $1000 п Ф-0,047$ & 0,3 & $220-2200 \pi \Phi$ & 1 \\
\hline & 50 & 0,$015 ; 0,022(0,033)$ & $0,5(1)$ & & & & & $1000 n \Phi-0,022$ & 1 & & \\
\hline & & & & 0,022 & 1 & $1000 п Ф-0,068$ & 1 & 0,047 & 2 & 0,022 & 2 \\
\hline & & & & & & $560 п Ф-0,027$ & 0,3 & & & & \\
\hline & 100 & $00011 \Psi-0,01(0,010)$ & $0,3(1)$ & & & $1000 \sqcap \Phi-0,027$ & 1 & & & & \\
\hline & 16 & $3300 \pi \Phi$ & 3 & & & & & & & & \\
\hline $3,2 \times 1,25$ & 25 & $1500 ; 2200 \pi \Phi$ & 2 & & & & & & & & \\
\hline МП० & 50 & $1000 \sqcap \Phi$ & 2 & $22-220 \pi \Phi$ & 0,3 & & & & & & \\
\hline & 100 & $22-680 п Ф$ & $0,5-0,7$ & & & & & & & & \\
\hline & 16 & $0,1(0,15)$ & 3 & & & & & & & & \\
\hline & 25 & 0,$047 ; 0,068(0,1)$ & $1(3)$ & & & & & & & & \\
\hline $\begin{array}{l}3,2 \times 1,25 \\
(1205)\end{array}$ & 50 & (027) & $1(2)$ & $470 п Ф-$ & 0,3 & & & & & $220 \Pi \Phi-0,022$ & 1 \\
\hline $\mathrm{H} 20(\mathrm{H} 50)$ & & & & $0,022(0,047)$ & (l) & & & & & $0,01-1,0$ & 6 \\
\hline & 100 & $\begin{array}{c}1000 \Pi \Phi-0,015 \\
(0,022)\end{array}$ & $0,5(1)$ & & & & & & & & \\
\hline
\end{tabular}


Таблица 1. Продолжение

\begin{tabular}{|c|c|c|c|c|c|c|c|c|c|c|c|}
\hline \multirow{2}{*}{$\begin{array}{l}\text { Габарит, мм, } \\
\text { (код), } \\
\text { группа ТКЕ }\end{array}$} & \multirow{2}{*}{$\begin{array}{c}U, \\
B\end{array}$} & \multicolumn{2}{|l|}{ Б33 } & \multicolumn{2}{|c|}{ API (Spectrum Control) } & \multicolumn{2}{|l|}{ Syfer } & \multicolumn{2}{|l|}{ AVX } & \multicolumn{2}{|l|}{ Murata } \\
\hline & & $\begin{array}{c}C, \\
\operatorname{MK} \Phi\end{array}$ & $\begin{array}{c}\mathrm{I}_{\text {ном' }} \\
\mathrm{A}\end{array}$ & $\begin{array}{c}C, \\
\text { MKФ }\end{array}$ & $\begin{array}{c}\mathrm{I}_{\text {макс' }} \\
\mathrm{A}\end{array}$ & $\begin{array}{c}C, \\
\text { MKФ }\end{array}$ & $\begin{array}{c}I_{\text {макс' }} \\
\mathrm{A}\end{array}$ & $\begin{array}{c}C, \\
\text { MKФ }\end{array}$ & $\begin{array}{c}I_{\text {макс' }} \\
A\end{array}$ & $\begin{array}{c}C, \\
\text { MKФ }\end{array}$ & $\begin{array}{c}I_{\text {макс' }} \\
A\end{array}$ \\
\hline \multirow{8}{*}{$\begin{array}{l}3,2 \times 1,6 \\
(1206) \\
\text { МП0 }\end{array}$} & 16 & $4700 \sqcap \Phi$ & 3 & & & & & & & & \\
\hline & 25 & $3300 \sqcap \Phi$ & \multirow{3}{*}{2} & & & 560-3900 ПФ & 0,$3 ; 2$ & & & & \\
\hline & \multirow{2}{*}{50} & \multirow{2}{*}{$2200 \Pi \Phi$} & & & & 22-3300 пФ & 0,3 & & & & \\
\hline & & & & & & $22-1000$ пФ & 2 & & & & \\
\hline & \multirow{2}{*}{100} & \multirow{2}{*}{ 220-1500 ПФ } & & & & $22-2200 п Ф$ & 0,3 & \multirow{2}{*}{$22-470 п \Phi$} & \multirow{2}{*}{0,3} & & \\
\hline & & & 1 & & & $22-560 п \Phi$ & 2 & & & & \\
\hline & \multirow{2}{*}{250} & \multirow{2}{*}{$22-150 п Ф$} & & & & $56-100 п Ф$ & 0,3 & & & & \\
\hline & & & & & & $15-180$ пФ & 2 & & & & \\
\hline \multirow{9}{*}{$\begin{array}{l}3,2 \times 1,6 \\
(1206), \\
\mathrm{H} 20(\mathrm{H} 50)\end{array}$} & 16 & $0,15(0,22)$ & 3 & & & & & & & & \\
\hline & \multirow{2}{*}{25} & \multirow{2}{*}{$\begin{array}{c}0,068 ; 0,1 \\
(0,15)\end{array}$} & \multirow{2}{*}{$2(3)$} & & & $5600 п \Phi-0,33$ & 0,3 & & & & \\
\hline & & & & & & $0,01-0,33$ & 2 & & & & \\
\hline & \multirow{2}{*}{50} & \multirow{2}{*}{$\begin{array}{c}0,047 \\
(0,068)\end{array}$} & \multirow{2}{*}{2} & & & $4700 п Ф-0,22$ & 0,3 & 1000 口巾-0047 & 03 & & \\
\hline & & & & & & $0,01-0,22$ & 2 & & (5) & & \\
\hline & 100 & $2200 \sqcap \Phi-0,033$ & 07 (2) & & & $1800 п Ф-0,1$ & 0,3 & & & & \\
\hline & 200 & $(0,047)$ & 年 & & & $0,01-0,1$ & 2 & & & & \\
\hline & 250 & 680-1 $500 \sqcap \Phi$ & & & & $2700 \sqcap \Phi-0,056$ & 0,3 & & & & \\
\hline & 200 & $(2200 \sqcap \Phi)$ & (5, & & & $0,012-0,056$ & 2 & & & & \\
\hline & 16 & $6800 \Pi \Phi$ & & & & & & & & & \\
\hline & 25 & $4700 \sqcap \Phi$ & 2 & & & 820-4 700 пФ & 0,$3 ; 2$ & & & & \\
\hline & & & & & & 22-3900 пФ & 0,3 & & & & \\
\hline $4,5 \times 1,6$ & & & & & & $100-2200$ пФ & 2 & & & & \\
\hline мпо & 100 & $330-2200$ Ф & 2 & 22-470مه & 03 & 22-3300 пФ & 0,3 & & & & \\
\hline & & & & & & $100-680 п Ф$ & 2 & & & & \\
\hline & 250 & ד & I & & & 560-1200 пФ & 0,3 & & & & \\
\hline & & & & & & $56-470 п Ф$ & 2 & & & & \\
\hline & 16 & $0,33(0,47)$ & 4 & & & & & & & & \\
\hline & & 0,$15 ; 0,22$ & 3 & & & $3900 п \Phi-0,56$ & 0,3 & & & & \\
\hline & 20 & $(0,33)$ & (4) & & & $0,022-0,56$ & 2 & & & & \\
\hline $4,5 \times 1,6$ & 50 & 0,$068 ; 0,1$ & 3 & 027 & 1 & $3300 \sqcap \Phi-0,33$ & 0,3 & & & & \\
\hline (1806), & & $(0,15)$ & (4) & & & $0,022-0,33$ & 2 & & & & \\
\hline $\mathrm{H} 20$ (H50) & 100 & $3300 \sqcap \Phi-0,047$ & $1-2$ & $1000 п Ф-$ & & $3300 \sqcap \Phi-0,18$ & 0,3 & & & $470 \sqcap \Phi-0,022$ & 0,3 \\
\hline & & $(0,068)$ & (3) & 0,022 & 0,5 & $0,022-0,18$ & 2 & & & $0,01-0,022$ & 6 \\
\hline & & $2200 \Pi \Phi$ & 0,5 & & & $2700 \sqcap \Phi-0,056$ & 0,3 & & & & \\
\hline & 230 & $(3300,4700$ пФ) & $(0,7)$ & & & $0,022-0,1$ & 2 & & & & \\
\hline $5,7 \times 5,0$ & 25 & $1 ; 1,5(2,2)$ & 6 & & & & & & & & \\
\hline $\mathrm{H} 20$ (H50) & 50 & $0,15-0,68(1 ; 1,5)$ & $4-5(6)$ & & & & & & & & \\
\hline
\end{tabular}




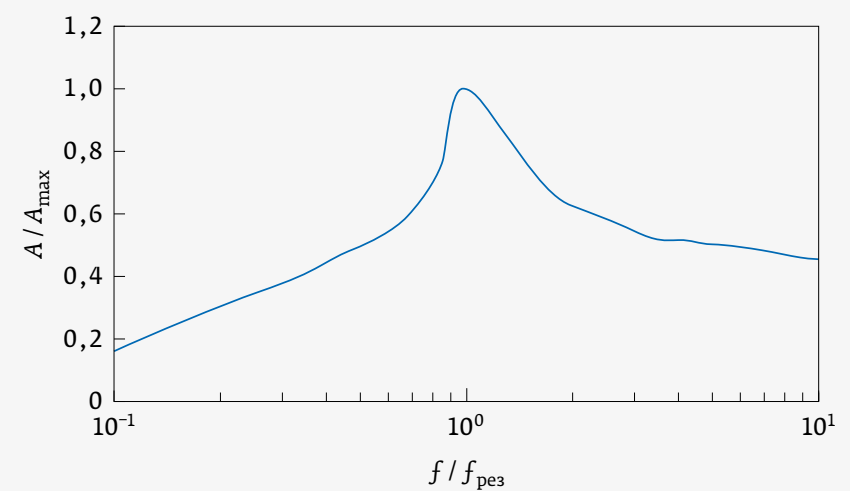

Рис. 4. Динамика изменения вносимого затухания фильтров С-типа в зависимости от частоты $\left(A_{\max }-\right.$ максимальный уровень $A$ на $f_{\text {рез }}$ )

На рис. 4 приведена АЧХ вносимого затухания, рассчитанная по формуле (1). Она соответствует частотной зависимости полного сопротивления Z (см. рис. 3): на частоте собственного последовательного резонанса $f_{\text {рез' }}$ где Z имеет минимальное значение, вносимое затухание достигает максимального значения. Иногда за $U_{1}$ принимают напряжение в цепи с фильтром, а за $U_{2}$ - напряжение без фильтра. От этого зависит, будет повышаться или уменьшаться вносимое затухание по мере увеличения частоты, и соответственно графические изображения их динамики.

Помимо открытого монтажа, при котором вносимое затухание фильтров начинает снижаться сразу после частоты $f_{\text {рез, }}$ существует метод экранированного

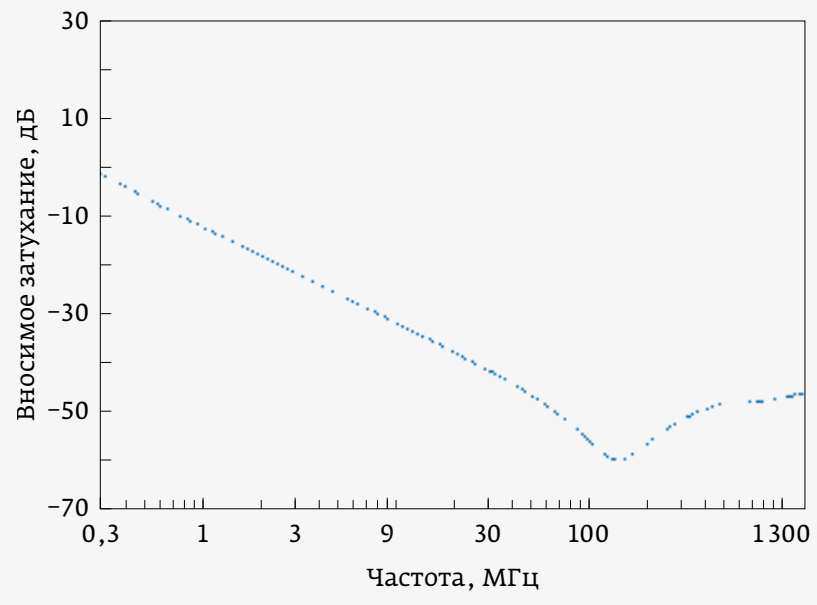

Рис. 5. Вносимое затухание фильтра Б33 с перегородкой (гр. H20, 4,5×1,6 мM, 0,022 мКФ) монтажа, позволяющий значительно повысить величину вносимого затухания относительно частоты резонанса. Характер АчХ (рис. 5) при этом подобен АЧХ навесных фильтров в металлических корпусах с резьбовым креплением. Для применения данного способа монтажа следует разделять проходные выводы фильтра металлической перегородкой. Однако в силу сложности метод экранированного монтажа не находит широкого применения [2].

Вносимое затухание в диапазоне частот от 0,3 до 3200 МГц определялось с помощью измерителей комплексных коэффициентов передачи “Обзор-103" и "Обзор-304». Фильтры, смонтированные в соответствии с их габаритными размерами на специальные платы, были установлены в контейнер для измерения вносимого затухания (рис. 6). Соответствие контейнера требованиям ГОСТ [3] по КСВн (коэффициент стоячей волны не более 1,5) позволило повысить точность измерения характеристик АЧх.

Приборы «Обзор» предназначены для измерения комплексных $S$-параметров, из которых вносимому затуханию соответствует коэффициент передачи $S_{21}$, который определяется как отношение напряжения выходного сигнала без фильтра к напряжению с подключенным фильтром. По значению $S_{21}$ на частоте резонанса было определено эквивалентное последовательное сопротивление $\mathrm{R}_{\text {эпс }}$ (см. рис. 3) по следующей формуле:

$$
\mathrm{R}_{\ni \Pi \mathrm{C}}=\frac{\mathrm{Z}_{0}}{2 \cdot 10^{\frac{-S_{21}}{20}}}(\mathrm{OM}) .
$$

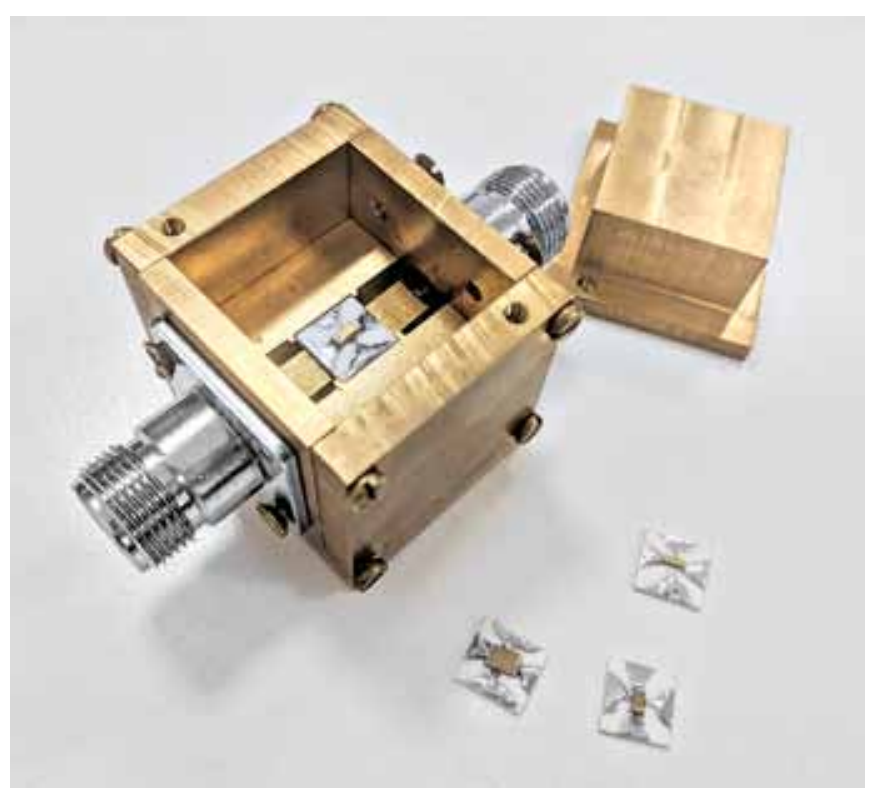

Рис. 6. Контейнер для измерения вносимого затухания фильтров Б33 


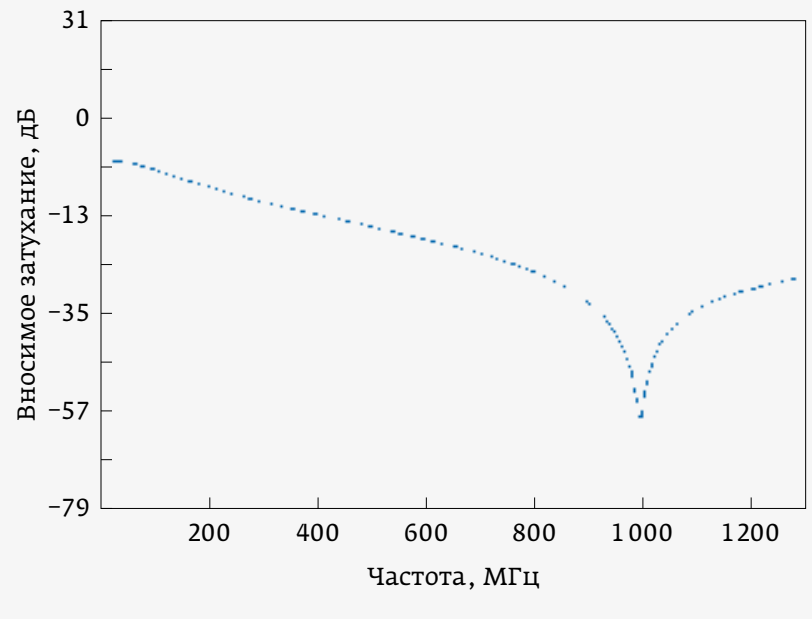

Рис. 7. Вносимое затухание фильтра Б33, линейная шкала (гр. МП0, 3,2×1,6 мм, 47 пФ, $f_{\text {рез }}=996$ МГц)

На рис. 7 и 8 приведены полученные с помощью этих приборов АЧХ фильтров емкостью 47 пФ и 2,2 мкФ.

Для фильтров 533 более удобной и информативной оказалась табличная форма представления Ачх (табл. 2). Так как фактические значения емкости фильтров отличаются от их номинального значения в пределах допустимого отклонения, для минимизации погрешности при обработке результатов значения резонансной частоты $f_{\text {рез }}$ были пересчитаны для каждого значения номинальной емкости.

Частота среза АЧХ, при которой вносимое затухание А равняется 3 дБ, достаточно точно соответствовала соотношению:

$$
f_{c}=1 / \pi R C,
$$

где $f_{c}$ - частота среза (Гц), R- сопротивление измерительной системы (50 Ом), C - емкость фильтра (Ф).

Зависимость частоты среза от $\mathrm{C}_{\text {ном }}$ представлена на рис. 9.

Значения параметров помехоподавления $A, A_{\text {рез }}, f_{c^{\prime}}, f_{\text {рез }}$ в основном зависят от фактическихзначений емкости, на которых, в свою очередь, оказывают влияние окружающая температура и рабочее напряжение. Емкость фильтров группы МПо не зависит ни от температуры, ни от напряжения. Фильтры групп Н20, Н50 изготовлены на основе титаната бария с различными добавками. Такие керамические материалы отличаются высокой диэлектрической проницаемостью и сильно выраженной зависимостью емкости от температуры и постоянного напряжения. Поэтому для фильтров 533 не применялись материалы групп Н70 и Н90, где такие зависимости максимальны. Исходя из вышесказанного для получения наиболее точных значений параметров $A, A_{\text {рез }} f_{c^{\prime}} f_{\text {рез }}$ следует

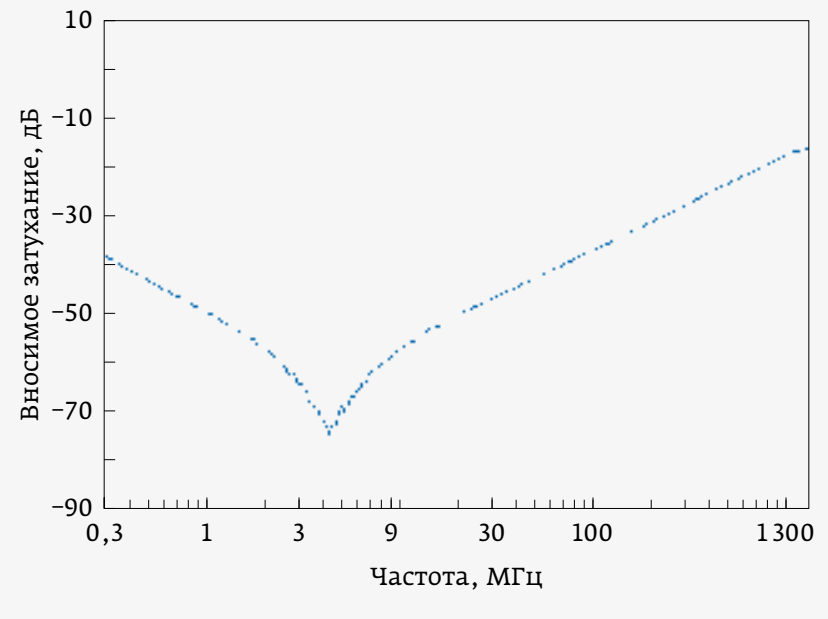

Рис. 8. Вносимое затухание фильтра Б33, логарифмическая шкала (гр. Н50, 5,7×5,0 мм, 2,2 мкФ, $f_{\text {рез }}=4,51$ МГц)

в табл. 2 вместо значений $\mathrm{C}_{\text {ном }}$ использовать фактические значения емкости. Зависимости емкости фильтров групп Н20, Н50 от температуры и постоянного напряжения представлены на рис. 10 и 11.

Для чип-фильтров, как и обычных керамических конденсаторов, характерна низкая теплопроводность. При их резком нагревании или охлаждении температура корпуса фильтра в разных точках различается, что приводит к механическим напряжениям, может вызвать трещины и разрушение. Особенно это критично для фильтров групп ТСЕ Н20, Н50. Поэтому при пайке устройств необходимо предусмотреть их постепенный нагрев, как и для обычных керамических конденсаторов этих групп.

В заключение следует отметить, что фильтры 533 не уступают импортным аналогам по своим

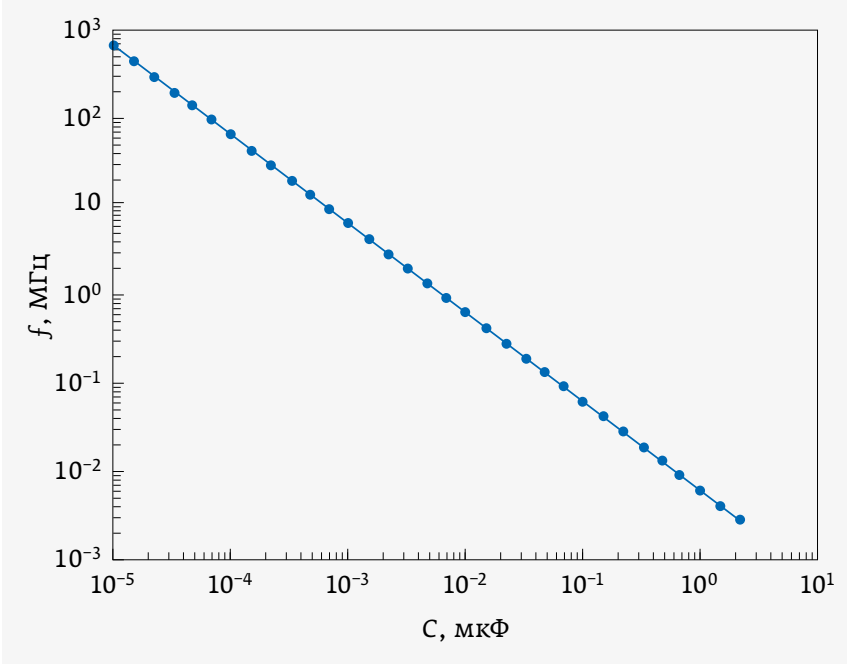

Рис. 9. Зависимость $f_{c}$ от номинальной емкости 
Таблица 2. Вносимое затухание на резонансной частоте фильтров Б33

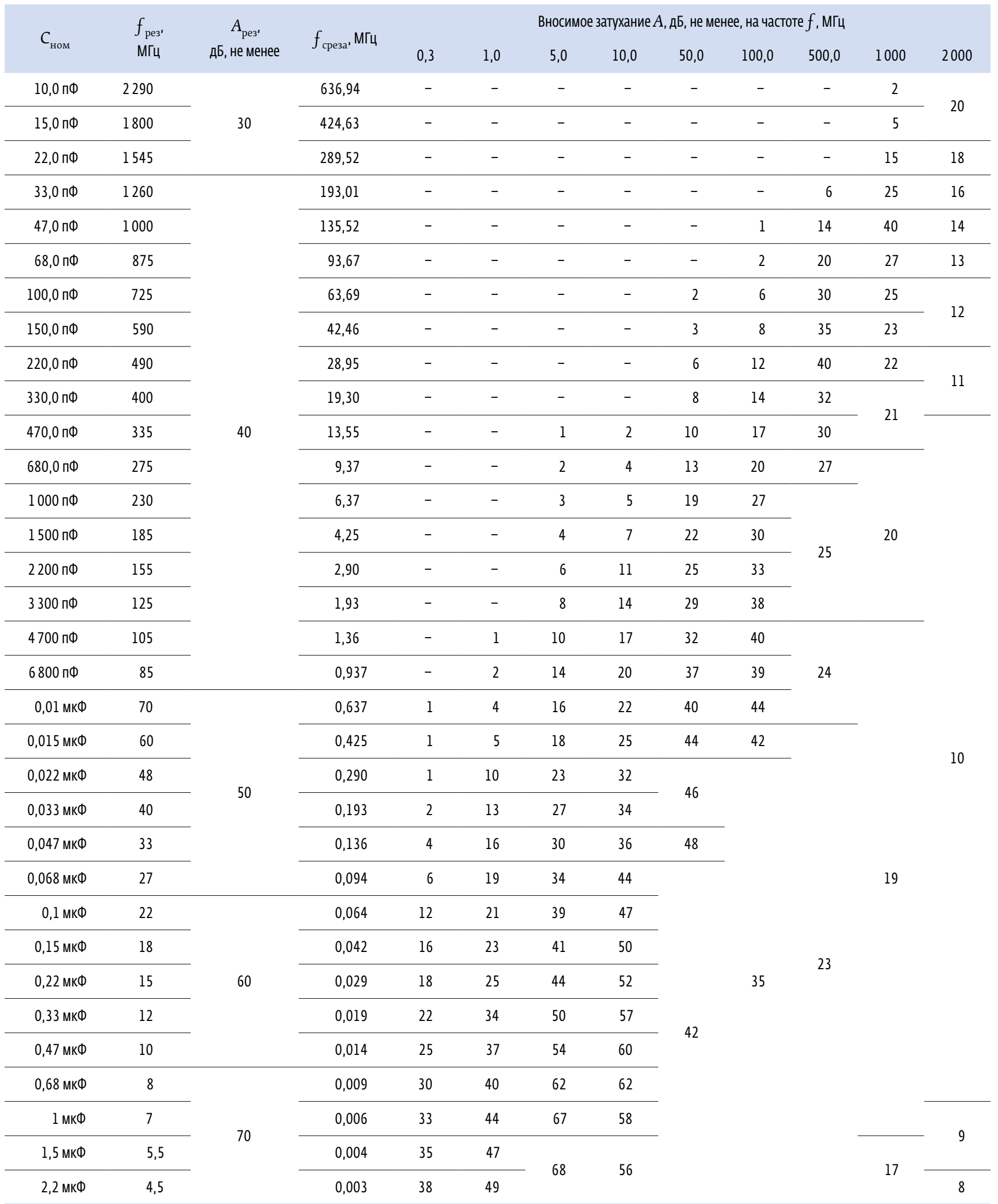

Примечание. Значения $f_{\text {рез }}$ приведены для номинальной емкости $C_{\text {ном }}$. Для фактической емкости $f_{\text {рез }}$ может отличаться в пределах $\pm 20 \%$ от указанных значений. 


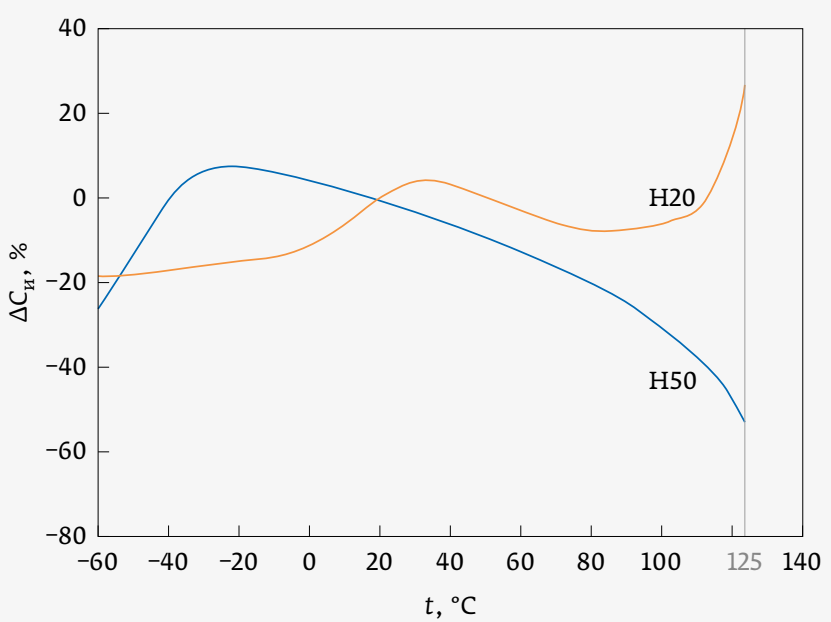

Рис. 10. Зависимость емкости от изменения температуры

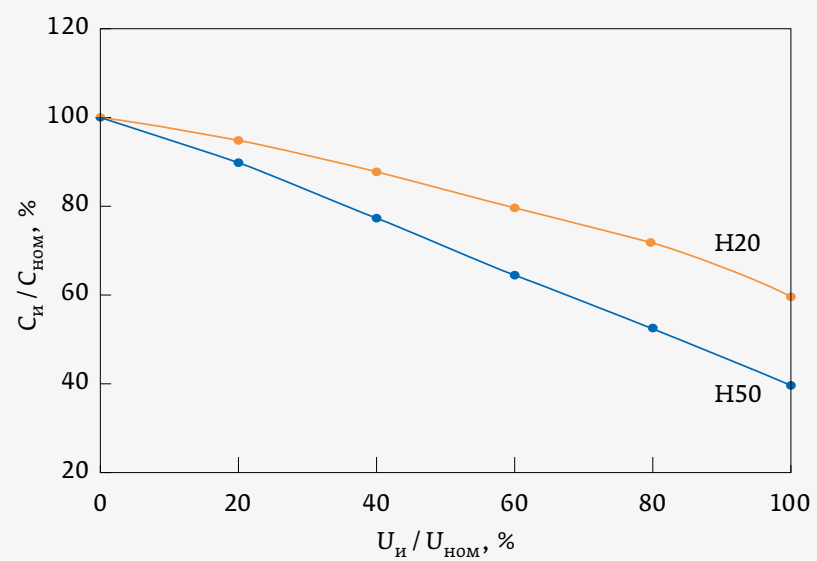

Рис. 11. Зависимость емкости от изменения напряжения

характеристикам, отличаются высокими значениями вносимого затухания, освоены АО «НИИ «Гириконд" в производстве с приемкой ОТК и могут использоваться в рамках импортозамещения. Выпуск продукции с приемкой ВП запланирован на 2020 год.

\section{ЛИТЕРАТУРА}

1. Фильтры нижних частот Б33, технические условия АДПК. 431145.007 TУ.

2. www.knowlescapacitors.com/getattachment/Products/ EMI-Filters/SMD-C-Filters/EMI-Filters.pdf.aspx

3. Пассивные помехоподавляющие фильтры и элементы. Методы измерения вносимого затухания. ГОСт 13661-92, Комитет стандартизации и метрологии СССР, Москва.

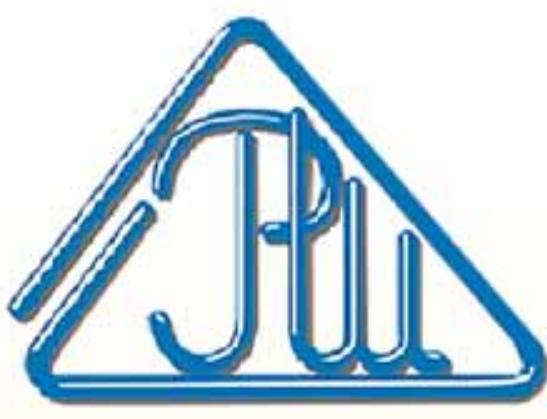

\section{Аргоновая СВЧ плазма}

\section{Патент №2657899 от 18.06.2018}

Сертифирована система менджмента качества по гражданской и оборонной тематике:

ГОСТ Р ИСО $9001-2015$ и ГОСТ РВ 0015-002-2012

Контродь за изготовлением оборонной продукции осуществляет отдел 200 ВП МО РФ

\section{ПоАробную информацию} можно узнать у нас на сайте

ООО АРупев-Шиамен 125130, r. MOCKBO, ул. Киары Цеткин, А. 33 , корп. 35, эт. 2 . nomeil. VI, KOMH, 9 T
Ten: (495) 787-63-67 фakc: (495) 787-63-68 e-mail: adc errudshel.ru www.rudshel.ru 